\title{
Rethinking bibliometric data concerning gender studies: A response to Söderlund and Madison
}

Silje Lundgren, Margrit Shildrick and David Lawrence

\author{
Linköping University Post Print
}

\section{Tweet}

N.B.: When citing this work, cite the original article.

The original publication is available at www.springerlink.com:

Silje Lundgren, Margrit Shildrick and David Lawrence, Rethinking bibliometric data concerning gender studies: A response to Söderlund and Madison, 2015, Scientometrics, (105), 3, 1389-1398.

http://dx.doi.org/10.1007/s11192-015-1767-3

Copyright: Springer Verlag (Germany) / Akadmiai Kiad http://www.springerlink.com/?MUD=MP

Postprint available at: Linköping University Electronic Press

http://urn.kb.se/resolve?urn=urn:nbn:se:liu:diva-121867 


\section{Rethinking bibliometric data concerning gender studies: a response to Söderlund and Madison}

Silje Lundgren, PhD, Research Coordinator, Tema Genus, Linköping University

Margrit Shildrick, Prof. of Gender and Knowledge Production, Tema Genus, Linköping University

David Lawrence, PhD, Head of Dept. of Publishing Infrastructure, Linköping University

We welcome this opportunity to respond to the article by Therese Söderlund and Guy Madison (2015) which we have found highly problematic and misleading as to the state of gender studies' publications in Sweden. From the position of relevant expertise - we are, a Gender Research Coordinator, a Professor of Gender and Knowledge Production and a Head of Publishing Infrastructure with bibliometric expertise - we offer a critique of the present study and some suggestions of alternative ways forward.

\section{The object of study: terms to denominate the field, keywords to make the selection, methods for sample selection.}

The major claim of Söderlund \& Madison's study is to ‘compile all scholarly gender studies literature produced by authors based in Sweden' (9). The authors argue that their methods make it 'feasible to cover the entire population of gender studies publications' (3), and that the database that is set up 'provides a representative and exhaustive compilation of contemporary publications in the field of gender studies by authors based in Sweden' (43). These claims relate to a number of methodological problems underlying the study that are partially acknowledged by the authors.

Gender studies is a field of research that has been transformed during the period 2000-2011 that the study addresses. It was characterized by intensive debates both on concepts - such as the ongoing strong critique of the concept 'gender' - and the development of intersectionality research that explicitly takes on intersections between categorizations such as gender, sexualities, 'race', ethnicity, class, dis/ability, etc (Lykke 2010). The period also saw changes in the role of gender studies as on the one hand institutionalized as a singular academic discipline with an explicitly inter- and transdisciplinary character, and on the other hand the parallel development of gender perspectives within other academic disciplines. These changes and developments have had a profound impact on what counts as a 'gender studies publication' or 'gender research', which, we believe is inadequately addressed in the selection procedure of the study.

As it stands, the mix of search criteria in different databases (e.g. keyword 'gender' in WoS and subject area 'gender studies' in DiVA) is problematic as the compilation of material thus covers quite distinct fields in the respective databases. The search in WoS for publications with the keyword 'gender' would yield a result covering 'research on gender' in a limited amount of international publications. In DiVA, the authors searched for publications classified under the research area 'gender studies', but thereby excluded gender research publications from any other relevant research area. In other words, these search criteria miss the complexity and inter/transdiciplinary character of gender research within academic disciplines other than gender studies per se. In the specific study, the authors state: 'The overall purpose...is to describe the gender studies literature' (p2). The object of analysis changes, however, throughout the article encompassing and putatively analysing 'gender studies publications', ‘scholarly publications on gender', 'gender research', 'gender studies research', 'gender studies', or 'publications concerning gender', terms that are used interchangeably and without comment on their relation. The description of the material covered is contradictory throughout - an inconsistency that makes it difficult to identify the object of analysis of the study, and to assess the results. Due to the mix of search criteria, the authors cannot claim that their study covers either 'gender research', 'research on gender', or 'gender studies publications' (based in Sweden) in an exhaustive manner.

In their choice of search criteria, Söderlund and Madison approach gender studies in an instrumentalist way as a sort of applied science, which has some validity and indeed is represented within gender studies itself of course, but they fail to see and reflect on the consequences of the limits it sets. The perspective is signaled when they offer a discussion about 'level of gender content' in the publications they analyse (12). To illustrate how Söderlund and Madison’s lack of knowledge of the field becomes an obstacle for their endeavour to establish a valid ground for their analysis, we shall spell out the problems here: 
What Söderlund and Madison refer to as the 'level of gender content' (p12) represents their reductionist and simplistic understanding of the classification which the Swedish researcher Hillevi Ganetz, now Professor of Gender Studies at Stockholm University, developed in a study (Ganetz 2005) of the way the so called 'gender marking' had been used in applications within the field of humanities and social sciences to the Swedish Research Council. The gender marking was an instrument, developed by the Research Council, to facilitate the organization of the assessment of applications. The implementation of the instrument meant that grant applicants, by a cross in a preformed space of the application form, were asked to indicate if the applied for research project was planned to involve 'questions pertaining to gender/gender perspectives' (Ganetz 2005: 6). The Research Council's Gender Studies Expert Committee commissioned Ganetz to analyse how the procedure had worked during its first year of implementation (2004). In order to make the rather broad and vague definition, 'questions pertaining to gender/gender perspectives' used in the Research Council's application forms, manageable in an analysis, Ganetz developed a three-part taxonomy: gender focus, gender perspectives and gender aspects (Ganetz 2005: 12f), which Söderlund and Madison have adopted for the purpose of their bibliometric analysis. It is, of course, per se reasonable to use an earlier taxonomy, developed by a gender studies scholar. However, while Ganetz meticulously discusses the limitations of her taxonomy and relates it very strictly to her specific purpose (the analysis of the gender markings of grant applications), Söderlund and Madison unreflectingly adopt it as though it were a generally applicable instrument. Moreover, they seriously distort Ganetz' conceptualization of the taxonomy, leaving out its key component. According to Ganetz, it is precisely NOT the quantitative 'level of gender content' that counts, but, on the contrary, whether the research demonstrates that the researchers 'are well versed in the research tradition [of gender studies], that they have an overview of the field and have knowledge about theory, methodology and empirical material within the field' (ibid: 13).

Söderlund and Madison's distortion of Ganetz' conceptual framework into a reductive instrumentalist approach reflects a worrying lack of understanding of the field in general and of the dimensions of the object of analysis, which, in turn, makes it impossible to assess which outputs should be deemed adequate to count as gender studies publications. For their analysis, the authors 'categorize publications from both [the Swedish and international] samples according to whether they use the term "gender" as in gender studies or in the sense of biological sex' (3). To this end, they have carried out a content analysis to assess 'whether [the research] applied a social construction perspective on gender or other intersectional perspectives' (8) - which warrants inclusion in their sample - or constituted articles on 'biological sex' - which are deemed 'irrelevant' for the study. The discussion in the article around the distinction between publications that approach gender as socially or culturally constructed, as opposed to biological sex, reflects an obsolete discussion within gender studies from the 1980s. It is telling that the articles - Bowles 1983 and Harding 1986 - that the authors rely on to aid the demarcation of the field of gender studies (7) both date from this period.

Söderlund and Madison do acknowledge that their selection process 'does not solve the central problem of how to define the "gender" in gender research' (8), but do not seem to recognize the implications. The debate around the very concept of 'gender' is of long-standing in the field of feminist-inspired and/or women-oriented research, and continues to be much critiqued to the extent that many scholars prefer not to use the term at all. For some, initially following Luce Irigaray (1993), the privileged term is sexual difference, while in more explicitly postmodernist accounts any implication of dualism is rejected in favour of a range of differences in which both sex and gender are positioned as having no greater consequence than other intersectional markers such as sexuality, disability, age or class. One hugely influential work has been Judith Butler's Gender Trouble (1990), which comprehensively undid the binary of sex and gender, while later work from the same author has rigorously engaged with intersectionality in a range of contexts (see Butler and Spivak 2007, Butler 2009).

Whatever approach to the problem is taken by individual scholars, what is important to remember is that just as academic 'women's' studies need not focus on the subject of women, so too 'gender' studies is just as likely to be inspired by broadly feminist theory, without directly addressing gender. Any bibliometric analysis that ignores the profound influence of the in-depth development of feminist theory and methodologies over the last 45 decades will surely miss a high proportion of research that simply could not have existed without that input. One of the present authors, as a Professor of Gender and Knowledge Production, uses the term gender very 
infrequently in research publications and yet is clear that her whole output is dependent on understanding knowledge production through years of immersion in feminist ways of thinking. And nor does the latter term imply that citations to feminist thought will predominate; it is a matter more of what resources one has developed that enable the scholar to launch critiques and suggest innovations across a broad range of concerns that relate to gender sometimes centrally, sometimes peripherally. Postconventional feminist scholars would claim that it is impossible to speak of disability, for example, without gender, or ethnicity, or age, or reproductive status being intersectional interests that are at least implicitly taken into account. The point is that 'gender studies' connotes a way of thinking, not a bounded subject matter, and, moreover, that the term gender studies, as it is used to denote the field, is commonly understood within the field as an umbrella term for a diversity of inter-, intra, in-between- and even postdisciplinary approaches, as theorized for example by Lykke (2010).

This raises the question of whether a research team without any expertise within the field of gender studies can properly conduct a bibliometric study that includes content analysis as a tool for selecting and determining which publications to include in the database. An analogy to the undertaking to distinguish between relevant publications that apply a 'social construction perspective on gender' and those other irrelevant publications that deal with so-called 'biological sex', would be to search for the keyword 'culture' in publications within anthropology or 'politics' within political science, to determine whether such publications could be said to 'belong' to their respective disciplines in an adequate manner. Interestingly, research on gender or the use of feminist perspectives within academic disciplines other than gender studies is often criticized for not being disciplinarily 'adequate' due to the application of non-traditional or non-familiar approaches or perspectives. It becomes ironic, then, or outright bizarre, when gender studies is assessed by scholars who do not know the field to determine which publications are considered to deal with 'gender' in a manner appropriate for classification within gender studies. Moreover, the selection procedure of the study has excluded a broad field of research areas arbitrarily deemed irrelevant to gender studies according to the authors, thus excluding a wide range of gender studies publications from their study base: 'For searches in WoS we used the keyword "gender' [...] due to an unsatisfactory and too wide Women's studies category, leading to an overly large number of less relevant hits' (10). Appendix B specifies which inappropriate fields were discounted from the initial search in WoS, including to our bewilderment, archeology, arts humanities, environmental sciences ecology, medical ethics, neurosciences, obstetrics, gynaecology, research experimental medicine, and transplantation.

It is difficult to understand, at least from the point of view of intersectionality, why the authors of the study should imagine that any area of scholarship in the life sciences in particular could be excluded. Of the present authors, Shildrick, for example, bases her major research in the arena of organ and tissue transplantation - which is explicitly excluded - where she works closely with both clinicians and visual artists. To date, and over a period of 7 years, at least 6 team papers have been published in conventional biomedical journals such as Transplantation; J. Heart and Lung Transplantation; BMJ; American J. of Transplantation (e.g. Shildrick et al 2009; Poole, Shildrick et al. 2010) - none of which would have showed up in the bibliometric analysis of WoS. The claim is not that gender has been the major driver of those publications, but that its significance is always part of the equation; and more to the point that Shildrick's own considerable contributions to the research are always deeply informed by feminist epistemologies. To exclude such clinical matters - though Shildrick herself is a philosopher - seems like a serious flaw in the bibliometric study and one that is undoubtedly repeated in regard to many other areas of the life sciences. There is, for example, now considerable work being done in the neurosciences that explicitly takes off from feminist thought (Bluhm et al. 2012; Dussauge and Kaiser 2012; Einstein 2012; Fine 2010; Kaiser and Dussauge 2015; Schmitz and Häppner 2014). Moreover, another excluded area - that of medical ethics - has a particularly strong and well-established record of intervention by feminist scholars, who publish both in mainstream journals and in the more dedicated International Journal of Feminist Approaches to Bioethics (Shildrick 2008; Zeiler 2009).

The dubious separation of the categories of sex and gender that the authors try to undertake is already highly problematic at a theoretical level, and becomes deeply blinkered in the context of clinical biomedicine and medical ethics where it is feminist-inspired researchers who are at the forefront of undoing the traditional belief that biological sex is a simple and stable given (e.g. Fausto-Sterling 2000; Fox Keller 2002). Body theory in 
general - which clearly includes biologically-based accounts - has been driven forward over the last few decades not just by feminist philosophers and cultural theorists, but by those who identify the biosciences as their primary discipline. And what we are learning is that biology itself is never separate from the implications of intersectionality (Grosz 2010).

In their initial comments to their selection procedure the authors state that 'The main inclusion criterion was that publications were considered to belong to the field of gender studies according to the academics within that field themselves' (9). As gender studies scholars we can conclude that this aim has not been achieved.

\section{Technical issues and the question of language in relation to international citations and impact factor}

From the point of view of standard bibliometrics analysis, the Söderlund and Madison paper falls well short of adequate good practice. As already mentioned, the credibility of the study depends entirely on the list of publications generated under the term "Gender Studies" which is very hard to define, but there are also any number of technical issues identified by Lawrence- who has established bibliometric expertise - about the search itself.

- The period 2000-2010 (and particularly 2000-2005) is covered unreliably in any publication database or index that Lawrence is aware of. Most of this search was conducted in 2011 when the reliability of publication databases and indexes was considerably worse than today to the point that local repositories at many Swedish universities did not cover the early part of the stated time range. Even now research group and individual researchers' website publications are notoriously unreliable, often selective in their coverage and inevitably out of date. As a consequence it would be fair to say that without contacting individual researchers and asking for complete, up-to-date information, there is no way to create a comprehensive list for publications in the area. It is also the case that book chapters in edited collections and monographs are very common in the social sciences and humanities, and may incorporate the most significant research in the field, yet their coverage is highly unreliable in all known databases.

- The results of this specific search illustrate the problems above. The KvinnSam database purports to be a summation of local repositories and /or research group websites, such that duplication between KvinnSam and university-based publication lists should be virtually $100 \%$. Similarly anything in Web of Science or Scopus should duplicate university lists, and one might also expect some duplication in individual university lists that reflected collaborative research across different institutions. In this study the number of duplicates recorded (750 out of 13000) is extremely low, raising the question of which detection technique was used and whether the resulting publication database SGSL is in any way comprehensive. In any case, detecting duplicates is often very difficult as a result of errors in bibliographical details in databases; the frequently sparse publication data given; and the general complexity of defining certain publication types, like book chapters.

- The search technique (effectively based on a single search term or subject area with no further development) is highly simplistic. If the objective is to accurately cover the diverse and complicated research area of Gender Studies - particularly when GS experts are not involved - then a far more advanced approach might be, for example, to take a nucleus, such as the one collected, and subject it to further rounds of analysis that expand results to include other publications missed in the initial search.

- Table B1 is rather misleading and confusing. The 13000 publications are divided (without duplication) between local university sources and the national or international databases KvinnSam and WoS. Note ' $c$ ' indicates that DiVA denotes publication in DiVA - there is, incidentally, no similar breakdown for the local repositories of the non-DiVA universities - but it is highly doubtful that so much was published in that database. Certainly there is no indication that so many original publications are attributable to Gender Studies in our own university's (LiU's) DiVA site. Perhaps this is a careless terminological issue where "published" simply means "registered". The "Hits" column which is passed off as a distribution of publications, is in reality perhaps a distribution of where publications were found after duplicates were removed, a distribution perhaps not so interesting since it would depend on the order in which the searching was done (i.e. the order in which the databases/indexes were searched) since anything already found in e.g. KvinnSam does not count again under "Linköping". And again the 
fact that 111 publications are listed under LiU appears to indicate that these are not in KvinnSam leading one to strongly question the coverage of any of the databases used. Moreover, we know for certain that LiU's DiVA could not be considered comprehensive in 2011 for publications going back to 2000, including for Gender Studies. The 85 publications listed for 2000-2011 might reasonably be the output of a single professor and yet during that same period Tema Genus expanded from 10 to 30 researchers. (Even so 111 publications were found that were not in KvinnSam, indicating that that source is not the comprehensive either).

- Many searches made use of database “subject areas”. It should be noted, however, that WoS and Scopus apply no more than 3 subject classifications at the journal level, which notoriously misses multidisciplinary or broad-based journals. Subject areas in local repositories are even more problematic. In essence - prior to very recent times - there has been no quality control of postings in local repositories at Swedish universities. Subject areas have often not been specified, or specified to only a very gross (i.e. top) level.

- $\quad$ Table 2 is difficult to understand and suffers from some of the same issues as B1. It is unclear what is indicated when the expected overlap between publications in WoS and KvinnSam and local "Institutions" is not given. It is very hard to believe that WoS publications were not registered locally. Table 2 also indicates that well over $50 \%$ of the journal articles were indexed by WoS. This is possibly true but Lawrence is highly skeptical, given a tendency to publish in niched, perhaps national, journals.

- The authors state that "45 of the Swedish journal articles” were not found in WoS, yet in table 2, the figure appears as 28+34. I.e. 62 articles, not in WoS. This type of discrepancy surely undermines the credibility of the study.

\section{Language, impact and citations}

The authors show (in terms of their own definition of which publications to include) that research on gender in Sweden is mainly found within the social sciences and humanities (8f), which often give priority to publishing in Swedish, which as they acknowledge, are generally less cited and spread than those written in English (37), and to a lesser extent are excluded in WoS (10).

They also stress that Sweden's gender studies research 'appears not to be the most prominent' because 'its production of the total national production is surpassed with up to 60\% by Australia, Canada, England, New Zealand, South Africa and the USA' (40).This is certainly one valid interpretation of Figure 3, which shows the number of gender studies publications across 13 countries in proportion of the total number of national academic publications in each country in 2012, although it could have been noted that the higher scoring countries all have English (by contrast to Sweden) as an official first or main language. In any case, there are alternative readings of the same Fig. 3: Swedish gender studies research is the top scorer, compared to other countries where English is not the official first or main language (Italy, Norway, Finland, and Israel), and it scores higher than some English speaking countries like Ireland.

In sum, however, the question of language does lead to lower international distribution and thus lower impact and international citations since many gender studies publications are not included in WoS. There are several other issues, but suffice it to say that with regard to the very broad area gender studies, the normalization of citations against subject area (or age or publication type for that matter) yields only very simplistic and misleading results.

\section{On gender studies and political ideology}

The article presents a number of statements that gender studies is 'intrinsically associated with feminism and political reforms' (abstract) and 'associated with a range of societal goals and a political ideology' (3). The conflation of the scholarly field of gender studies and political ideology reaches its peak when the authors write that gender studies has been 'implemented on many levels in [Swedish] society', which is illustrated (or evidenced) by brief quotes from three SOUs (government reports). Firstly, it is completely incomprehensible what the claim that gender studies has been 'implemented' in Swedish society means. Has political science been implemented in Swedish society? Or history, maybe? Secondly, it is highly questionable what random quotes 
from government reports are supposed to tell us about 'Swedish society' at large, and the conditions for academic publications within gender studies specifically. Interestingly, research within gender studies has long trajectory of critical analyses of state equality policies, and in particular of scrutinizing the assumptions made and concepts used in such government reports that are mentioned by the authors (e.g. Alm 2006; Andersson 2011; Edenheim 2005). Critical studies on gender equality in fact make up a substantial sub-field within gender studies.

The article furthermore makes the claim that 'in the whole world, Sweden may be one of the societies that is most sex egalitarian and also most sympathetic towards gender studies' (6). This is a startling statement on several levels. Many centres for gender studies in Sweden share experiences of hacked websites, harassment, death threats, protection by the Swedish security police Säpo, local and national media campaigns arguing for the closure of centres of genders studies and so on. Interestingly, the backlash against gender studies reached a peak during the time period covered by this study, namely 2005 and onwards, in the wake of the TV 'documentary' Könskriget. On a somewhat different level, research within gender studies in Sweden during the last decade has dedicated considerable scholarly attention to dismantling the very notion of Sweden as the most gender equal country in the world, commonly using postcolonial theory and critical whiteness studies to analyse how this idea of Sweden as a supposed icon of gender equality entails a process of othering and contributes to reproduce a notion of Swedish exceptionalism regarding racial hierarchies (Lundström and Hübinette 2011; de los Reyes and Mulinari 2005; Keskinen 2009). To summarize, there is an ample body research within gender studies that critically analyses those very statements and institutional conditions that the authors use to shortcircuit their argument about the conditions for publications on gender/within gender studies in Sweden.

We cannot ignore what seems to be an underlying bias in the article, which is most clearly reflected when in the conclusions the authors include speculations that they explicitly acknowledge are unsubstantiated. For instance they state; 'Its political agenda might render gender studies less relevant for many scholars, either because they do not share the ideological outlook on the same phenomena that they study from other vantage points, or because it renders publications an impression of being biased towards certain conclusions predicated upon the ideology. These questions are obviously difficult to answer, because they relate to processes that we have no data on' (41). We do not know which audience the authors have in mind, therefore it might be relevant to include some comments from the peer evaluation undertaken by an international expert panel within gender studies of the three Centres of Gender Excellence at Swedish universities (Swedish Research Council 2011). ${ }^{1}$ The evaluation assessed the overall quality of the research, including the output in terms of publications, as ranging from very good to outstanding, establishing 'both nationally and internationally renowned environments for gender research ' (ibid: 8) and in some cases even attaining 'a notable position in the international context of gender research' (ibid: 16) despite the fact that, as underlined by The Research Council's international peer evaluation panel, the grant period of 'five years is a rather short period to achieve a sustainable and international attractive research environment' (ibid: 8).

For the future, we strongly believe that the database of this study is an important initiative that might be very useful once the methodological problems have been recognized and rigorously remedied along the lines of our discussion. We therefore thank the authors for their offer to make the database freely available to the research community and to update and develop its taxonomies. We would be most willing to help develop better and more inclusive search criteria to attune them to the stated aims behind the current compilation of publications. We look forward to the emergence of in-depth analyses of gender studies publications that more reflect the dynamic character of the field of study.

\section{References: ${ }^{\mathrm{i}}$}

*Alm, E. (2006). "Ett emballage för inälvor och emotioner" : föreställningar om kroppen i statliga utredningar från 1960- och 1970- talen. Gothenburg: Gothenburg University.

\footnotetext{
${ }^{1}$ Our university was among those rewarded funding from the Swedish Research Council to establish a Centre of Gender Excellence (Linköping together with Örebro University) for the period 2007-2011 (SEK 27 million in total during the fiveyear period).
} 
*Andersson, C. (2011). Hundra år av tvåsamhet : äktenskapet i svenska statliga utredningar 1909-2009. Uppsala: Uppsala University.

Bluhm, R., Jaap Jacobson, A. \& Maibom, H. L. (Eds.) (2012) Neurofeminism: issues at the intersection of feminist theory and cognitive science. Basingstoke: Palgrave Macmillan.

Bowles, G. (1983). Is Women's Studies an academic discipline? In G. Bowles \& R. D. Klein (Eds.), Theories of women's studies (pp. 32-45). London: Routledge \& Kegan Paul.

Butler, J. (1990). Gender trouble: feminism and the subversion of identity. New York: Routledge

Butler, J. (2009). Frames of war: when is life grievable?. London: Verso.

Butler, J. \& Spivak, G. C. (2007). Who sings the nation-state?: language, politics, belonging. London: Seagull.

*de los Reyes, P. \& Mulinari, D. (2005). Intersektionalitet - kritiska reflektioner över (o)jämlikhetens landskap.

Malmö: Liber.

*Dussauge, I. \& Kaiser, A. (2012). Neuroscience and Sex/Gender. Neuroethics, 5(3): 211-215.

* Edenheim, S. (2005). Begärets lagar: moderna statliga utredningar och heteronormativitetens genealogi. Lund: Lund University.

*Einstein, G. (2012). Situated neuroscience : exploring biologies of diversity. In R. Bluhm, A. Jaap Jacobson, \& H. L. Maibom (Eds.) Neurofeminism: issues at the intersection of feminist theory and cognitive science. (Pp.

145-176). Basingstoke: Palgrave Macmillan.

Fausto-Sterling, A. (2000). Sexing the body: gender politics and the construction of sexuality. New York: Basic Books.

Fine, C. (2010). Delusions of Gender: How Our Minds, Society, and Neurosexism Create Difference. New York: W. W. Norton.

Fox Keller, E. (2002). Making Sense of Life : Explaining Biological Development with Models, Metaphors, and Machines. Cambridge : Harvard University Press

Ganetz, H. (2005). Genusvetenskapliga projektansökningar inom humaniora-samhällsvetenskap - en uppföljning av Vetenskapsrådets beredning och utfall år 2004. Vetenskapsrådets kommitté för genusforskning,

Vetenskapsrådets Rapportserie 15: 2005.

Grosz, E. (2010). The Untimeliness of Feminist Theory. NORA - Nordic Journal of Feminist and Gender Research, 18(1), 48-51.

Harding, S. (1986). The science question in feminism. Ithaca: Cornell University Press.

* Hübinette, T. \& Lundström, C. (2011). Sweden after the Recent Election: The Double-Binding Power of Swedish Whiteness through the Mourning of the Loss of "Old Sweden" and the Passing of "Good Sweden".

NORA - Nordic Journal of Feminist and Gender Research, 19(1), 42-52

Irigaray, L. (1993). An Ethics of Sexual Difference. London: Athlone Press.

*Kaiser, A. \& Dussauge, I. (2015). Feminist and Queer Repoliticizations of the Brain. Lausanne: EspacesTemps.net

Keskinen, S. (Ed.) (2009). Complying with colonialism : gender, race and ethnicity in the Nordic region.

Aldershot: Ashgate.

*Lykke, N. (2010). Feminist Studies: A Guide to Intersectional Theory, Methodology and Writing. London:

Routledge. (Published also in Swedish (2009): Genusforskning. Stockholm: Liber.)

Poole, J., Shildrick, M., McKeever, P., Ross, H.J., Mauthner, O., De Luca, E., \& Abbey, S. (2010). The

Obligation to Say 'Thank-You'. Journal of Heart and Lung Transplantation,

doi: http://dx.doi.org/10.1016/j.healun.2009.11.172

Schmitz, S. \& Höppner, G. (Eds.) (2014). Gendered Neurocultures. Feminist and Queer Perspectives on Current Brain Discourses. Vienna: Zaglossus.

*Shildrick, M. (2008). The Critical Turn in Feminist Bioethics: the case of heart transplantation. International Journal of Feminist Approaches to Bioethics, 04/2008; 1(1):28-47. doi: 10.1353/ijf.0.0013

Shildrick M., McKeever, P., Abbey, S., Poole, J., \& Ross, H. (2009). Troubling Dimensions of Heart Transplantation. Medical Humanities 2009; 35:35-38 doi:10.1136/jmh.2008.001073

Swedish Research Council (2011). Evaluation of "Centres of Gender Excellence”' (5:2011). Stockholm:

Swedish Research Council.

Söderlund, T. \& Madison, G. (2015). Characteristics of gender studies publications: A bibliometric analysis based on a Swedish population database. Scientometrics 2015. 
*Zeiler, K. (2009). Deadly Pluralism? Why Death Concept, Death Definition, Death Criterion and Death Test Pluralism Should Be Allowed, Even Though It Evokes Some Problems. Bioethics, 23, 450-459.

${ }^{\mathrm{i}}$ The starred references relate to researchers active in Sweden. 